NOTICE: this is the author's version of a work that was accepted for publication in Materials and Design. Changes resulting from the publishing process, such as peer review, editing, corrections, structural formatting, and other quality control mechanisms may not be reflected in this document. Changes may have been made to this work since it was submitted for publication. A definitive version was subsequently published in Materials and Design, Vol. 50 (2013). DOI: http://dx.doi.org/10.1016/j.matdes.2013.03.063 


\section{Accepted Manuscript}

Technical Report

Deflection hardening behaviour of short fibre reinforced fly ash based geopol-

ymer composites

F.U.A. Shaikh

PII:

S0261-3069(13)00263-X

DOI: http://dx.doi.org/10.1016/j.matdes.2013.03.063

Reference:

JMAD 5292

To appear in:

Materials and Design

Received Date:

10 February 2013

Accepted Date:

18 March 2013

Please cite this article as: Shaikh, F.U.A., Deflection hardening behaviour of short fibre reinforced fly ash based geopolymer composites, Materials and Design (2013), doi: http://dx.doi.org/10.1016/j.matdes.2013.03.063

This is a PDF file of an unedited manuscript that has been accepted for publication. As a service to our customers we are providing this early version of the manuscript. The manuscript will undergo copyediting, typesetting, and review of the resulting proof before it is published in its final form. Please note that during the production process errors may be discovered which could affect the content, and all legal disclaimers that apply to the journal pertain. 


\title{
Deflection hardening behaviour of short fibre reinforced fly ash based geopolymer composites
}

\author{
F. U. A. Shaikh \\ Dept. of Civil Engineering, Curtin University, Perth, Australia. \\ GPO Box U1987, Perth, WA 6845, Australia. \\ Curtin University \\ Tel | +61 892669054 \\ Fax $\mid+61892662681$ \\ Email| s.ahmed@curtin.edu.au
}

\section{Abstract:}

This paper reports the newly developed ductile fibre reinforced geopolymer composite (DFRGC) exhibiting deflection hardening and multiple cracking behaviour. The binder of the above composite is different from that used in conventional cement based system. The class F fly ash is used instead of Portland cement in DFRGC and is activated by alkaline liquids (sodium hydroxide and sodium silicate). In this study, two types of fibers namely steel (ST) and polyvinyl alcohol (PVA) fibres are used in mono as well as in ST-PVA hybrid form, with a total volume fraction of $2 \%$. The deflection hardening behaviour of newly developed DFRGC is also compared with that of conventional ductile fibre reinforced cementitious composites (DFRCC). The effects of two different sizes of sand $(1.18 \mathrm{~mm}$, and $0.6 \mathrm{~mm}$ ) and sand/binder ratios of 0.5 and 0.75 on the deflection hardening and multiple cracking behaviour of both DFRGC and DFRCC are also evaluated. Results revel that the deflection hardening and multiple cracking behaviour is achieved in geopolymer based DFRGC similar to that of cement based system. For a given sand size and sand content, comparable deflection hardening behaviour, ultimate flexural strength and the deflection at peak load are observed in both cement and geo-polymer based composites irrespective of fibre types and combination. The deflection hardening behaviour of DFRGC is also confirmed by the calculated toughness index values of $I_{20}>20$. The scanning electron microscope (SEM) study shows no degradation of PVA and steel fibres in the geopolymer matrix. However, the bond of PVA fibre with geopolymer matrix is found to be higher than that with cement matrix as evidenced in the SEM pictures. An opposite trend is observed with steel fibre. The proposed development exhibit a significant benefit for the use of geopolymer based DFRGC over cement based system as the former one is green in terms of no cement use.

Keywords: Geopolymer, deflection hardening, fibre, composites, fly ash, multiple cracking. 


\section{Introduction}

High performance fibre reinforced cementitious composites (HPFRCC) have been steadily developed in the last two decades. One of the main features of HPFRCC is its strain hardening and multiple cracking behaviours in both tension and bending [1]. It is a short fibre (metallic and/or non-metallic) reinforced cement based composites where fibre content between $2 \%$ and $3 \%$ by volume appears to be the most attractive due to ease of processing. Great interest in this area is observed through the development of engineered cementitious composites (ECC) [2] and ductile fibre reinforced cementitious composites (DFRCC) [3]. DFRCC is cement based composite reinforced with short random fibres which exhibits deflection-hardening and multiple-cracking behaviours in bending. It is a special class of HPFRCC that has higher deflection capacity at peak load than that of regular fibre reinforced concrete (FRC) and exhibit deflection hardening and multiple cracking behaviours. However, current version of DFRCC is limited to cement rich matrix, although the replacement of cement with fly ash is reported in few studies [4].

The need for environmentally friendly construction materials for sustainable development is an important issue in the present time. The concrete industry is said to be one of the significant contributors of global warming. This fact is due to the use of Portland cement as the main component in making concrete and cement based composites. The cement industry is responsible for about $6 \%$ of the $\mathrm{CO}_{2}$ emission, which is the main cause of the global warming. However, the use of concrete and cement based composites as the most widely used construction materials are still unavoidable in the foreseeable future. In this respect, the efforts of using supplementary cementitious materials or finding alternatives to Portland cement are necessary. The introduction of "geo-polymers" as a novel binder promises to be a good prospect for introduction into the concrete industry as an alternative to Portland cement. Geo-polymer concrete is a 'new' material that does not use Portland cement as a binder. Instead, a source of material such as fly ash, that is rich in Silicon (Si) and Aluminium (Al), is reacted by alkaline liquids to produce the binder [5]. Considerable researches have been conducted on geopolymer concrete [6]. However, very little is reported on the fibre reinforced geopolymeric composites [7-13] and fracture behaviour of geopolymer concrete [14-15]. None of the above studies reported deflection hardening or strain hardening behaviour in bending or tension.

This paper reports the deflection hardening and multiple cracking behaviour of short fibre reinforced geopolymer composites where the cement based binder is replaced by the fly ash 
based geopolymer binder. The fly ash is activated by alkaline liquids (sodium hydroxide and sodium silicate). The newly developed ductile fibre reinforced geopolymer composite (DFRGC) exhibited comparable and even better deflection hardening behaviour than its counterpart DFRCC in bending. The newly developed DFRGC is the first of its kind in the field of HPFRCC where Portland cement is completely replaced by class F fly ash. The effect of sand contents and its sizes on the deflection hardening behaviour of DFRGC is also evaluated in this study.

\section{Experimental Program}

The experimental program was divided into two parts. The first part was cement based DFRCC while the second part was geopolymer based DFRGC. In each part four series of composites were cast and tested in four point bending. In each series three mixes were considered. The first mix contained $2 \%$ steel (ST) fibre by volume, while the other two contained $2 \%$ polyvinyl alcohol (PVA) fibre and hybrid combination of $1 \% \mathrm{ST}+1 \% \mathrm{PVA}$ fibre. The effects of sand sizes (maximum sand sizes of $0.6 \mathrm{~mm}$ and $1.18 \mathrm{~mm}$ ) and sand/binder ratio ( $\mathrm{S} / \mathrm{B}=0.5$ and $\mathrm{S} / \mathrm{B}=0.75$ ) on the deflection hardening behaviour were also evaluated in both parts. Detail experimental program is shown in Table 1.

\section{Materials, mixing, curing and mix proportions}

The cement used in the study is general purpose (GP) Portland cement which corresponds to ASTM type I. The fly ash used is originated from Collie power station in Western Australia and satisfies ASTM class F classification. The fly ash consists of an amorphous part about $60 \%$ by wt. and a crystalline part about $40 \%$ by wt. [16]. The chemical composition of fly ash is shown in Table 2. The crystalline part of the fly ash has low reactivity and acts as fine aggregate in the binder system. The activating solutions used are sodium silicate with a chemical composition of (wt.\%): $\mathrm{Na}_{2} \mathrm{O}=14.7, \mathrm{SiO}_{2}=29.4$ and water=55.9. The other characteristics of the sodium silicate solution are specific gravity=1.53 g/cc and viscosity at $20^{\circ} \mathrm{C}=400 \mathrm{cp}$. The sodium hydroxide solution is prepared from analytical grade sodium hydroxide pellets. The mass of the $\mathrm{NaOH}$ solids in the solution varied depending on the concentration of the solution expressed in terms of molar, M. In this study, the $\mathrm{NaOH}$ solution with a concentration of $8 \mathrm{M}$ is considered and consisted of $8 \mathrm{X} 40=320 \mathrm{gms}$ of $\mathrm{NaOH}$ solids per litre of the solution, where 40 is the molecular weight of $\mathrm{NaOH}$. The $\mathrm{NaOH}$ (Sodium Hydroxide) is first mixed with de-ionized water with the ratio of 0.32:1 and produce 
sodium hydroxide solution. During the mixing of sodium hydroxide solution, the white sodium hydroxide pellets were slowly dissolved by the addition of de-ionized water. A rise of temperature occurred as the sodium hydroxide pellet slowly dissolved into solutions. And then the sodium hydroxide solution is mixed with $\mathrm{Na}_{2} \mathrm{SiO}_{3}$ (Sodium Silicate) with the ratio of 0.4:1 and produced the alkali activator. The alkali activator solution is then used for the mixing of geo-polymer based cementitious composites.

The mixing is carried out in a Hobart Mixer. First sand and cement or fly ash (in case of geopolymer matrix) are dry mixed for approximately three minutes and then water or alkaline activator solution (in case of geopolymer matrix) is slowly added into the mix and continues to mix for another three minutes. The fibres are then slowly added to the wet mix and continued mixing until the fibres are well dispersed in the mix. The DFRGC specimens were subjected to steam curing at $60^{\circ} \mathrm{C}$ immediately after casting, for 24 hours. The steam curing is carried out in the steam curing room in the laboratory. The specimens are then demolded after 24 hours and stored in the laboratory in open air until the date of testing. The DFRCC specimens are demolded after 24 hours and stored in the curing tanks where they are subjected to standard wet curing conditions. All specimens are tested after 28 days of casting.

Table 1 shows the mix proportions of both DFRCC and DFRGC. A constant W/C ratio of 0.45 is considered in DFRCC mixes and the same for alkali activator solution to fly ash ratio is also considered in the DFRGC mixes. This is deliberately selected for the ease of comparison between the two composites. The properties of fibres are shown in Table 3.

For each mix, three prismatic specimens of 20 X 75 X $300 \mathrm{~mm}$ in dimension are cast. All specimens are tested in four-point bending using an Instron testing machine under displacement control with a loading rate of $0.5 \mathrm{~mm} / \mathrm{min}$. A schematic of the bending test setup is shown in Fig. 1.

\section{Parameters describing the deflection hardening behaviour}

A typical deflection hardening response of DFRCC is shown in Fig. 2. The DFRCC exhibiting deflection hardening behaviour shows a higher load carrying capacity after the first cracking. In this research the first cracking point in the load-deflection curve is considered as the point where nonlinearity in the load-deflection curve becomes evident. This point is termed as limit of proportionality (LOP) according to the ASTM C1018-97. Researchers noticed difficulty of correctly identifying the first crack (peak) load of deflection hardening fiber reinforced cement composites [17]. In this study the method proposed by Kim et al. [17] 
is adopted to identify the LOP point in the load-deflection curve. The load value at LOP is termed as $\mathrm{P}_{\mathrm{LOP}}$ and the corresponding deflection value as LOP in Fig. 2. The modulus of rupture (MOR) also known as ultimate flexural strength is defined as the point where softening start in the load-deflection curve in Fig. 2.

One of the many advantages of deflection hardening fibre composite is its superior energy absorption capacity than that exhibits deflection softening behaviour. The energy absorption of fibre composite is also termed as toughness which is defined as the area under the load-deflection curve up to a given deflection. The current ASTM C 1609 specifies the deflection limit up to $1 / 150^{\text {th }}$ of the span. However, depending upon the composite's ductility this limit need to be adjusted and for deflection hardening fibre composite the limit of $1 / 50^{\text {th }}$ of the span can be adopted [18]. In this paper, the toughness of DFRCC and DFRGC is calculated as the area of the load-deflection (P- ) curve up to deflection corresponds to peak load and is termed as Tp. The toughness index (I), the ratio of area of the P- curve up to given deflection to that up to LOP, is also used to describe the deflection hardening [18]. The $\mathrm{I}_{\text {peak }}$ is the ratio of Tp to the area of the load-deflection curve up to LOP. The numerator of the index is considered the energy up to deflection corresponding to peak load and the denominator is considered the elastic energy. The higher the $\mathrm{I}_{\text {peak }}$ values the more ductile and the more deflection hardening the composite is. The toughness index values $I_{10}>10, I_{20}>20$, etc. is the indication of deflection hardening in fibre reinforced composites [18].

\section{Results:}

\subsection{Deflection hardening behaviour of mono fibre reinforced DFRGC}

The deflection hardening behaviour of DFRGC and DFRCC is shown in Figs. 3-4. Generally, the composite containing $2 \%$ steel (ST) fibre exhibited much higher modulus of rupture (MOR) that those containing PVA fibre of the same volume fraction irrespective of binder types, sand contents and sand sizes. However, its deflection capacity (deflection at peak load) is much lower than that containing PVA fibre. The higher MOR and the smaller deflection capacity of ST fibre reinforced DFRGC compared to its counterpart PVA fibre system is due to the high modulus of steel fibre. The lower MOR with considerable higher deflection capacity of PVA fibre reinforced composites is due to the low modulus of PVA fibres. Similar behaviour in both steel and PVA fibre reinforced cement based composites is 
also reported by other researcher [4]. The geopolymer based DFRGC exhibited comparable deflection hardening and multiple cracking behaviour to the cement based system.

\subsection{Deflection hardening behaviour of hybrid fibre reinforced DFRGC}

While the mono fibre reinforced DFRGC (containing one type of fibre (e.g. ST or PVA)) exhibited better deflection hardening behaviour than its cement based counterpart, the hybrid ST (1\%) and PVA (1\%) fibre reinforced DFRGC composited also exhibited superior deflection hardening behaviour than DFRCC and is shown in Figs. 5-6. Fig. 5 shows the flexural strength vs. mid span deflection curves of both DFRGC and DFRCC containing maximum sand size of $0.6 \mathrm{~mm}$. It can be seen that the DFRGC exhibited higher deflection capacity at peak load irrespective of sand/binder ratios compared to its counterpart DFRCC. Similar behaviour is also observed in the geopolymer composites containing maximum sand size of $1.18 \mathrm{~mm}$. By comparing Fig. 5 and 6 it can be seen that the deflection hardening behaviour of DFRGC containing coarse sand (e.g. maximum sand size of $1.18 \mathrm{~mm}$ ) can be enhanced by lowering the sand content.

\subsection{Effect of sand size and content on the deflection hardening behaviour:}

The effect of sand/binder ratios and sand sizes on the deflection hardening behaviour of DFRGC and DFRCC is also shown in Figs. 3-6. It can be seen that, by lowering the sand content ( $\mathrm{S} / \mathrm{B}=0.5)$, the improvement in the deflection hardening behaviour of DFRGC can be achieved irrespective of sand sizes (see Figs. 3-4). However, no such improvement is noticed in DFRCC composites. In case of ST fibre reinforced DFRCC the MOR is increased due to reduction of S/B ratio from 0.75 to 0.5 for both sand sizes. The same is also true for ST-PVA hybrid DFRCC. However, this phenomenon is not observed in PVA fibre reinforced DFRCC [19]. In the case of geopolymer composites mixed results are observed, the DFRGC containing maximum sand size of $0.6 \mathrm{~mm}$ exhibited higher MOR values at S/B ratio of 0.75 . An opposite trend is observed in the composite with maximum sand size of $1.18 \mathrm{~mm}$. The DFRGC reinforced with PVA and hybrid ST-PVA fibres didn't exhibit any remarkable difference in the MOR values in two different $\mathrm{S} / \mathrm{B}$ ratios.

The S/B ratio also influenced the deflection at peak load ( $\mathrm{Pp}$ ) in both composites. It is observed that by lowering the S/B ratio the $\mathrm{Pp}$ is increased in the ST fibre reinforced composites containing $0.6 \mathrm{~mm}$ size sand. Similar result is also observed in the geopolymer counterpart. However, in the case of composites containing $1.18 \mathrm{~mm}$ size sand no such 
improvement is observed. The PVA and hybrid ST-PVA fibre reinforced DFRCC and DFRGC exhibited similar behaviour where the $\mathrm{Pp}$ is increased by lowering the S/B ratio. Generally, the DFRGCs exhibited higher pp than DFRCC (see Fig. 7).

\subsection{Effect of geopolymer binder on the deflection hardening behaviour}

Generally, matrix plays an important role in the strain hardening behaviour of ductile fibre reinforced cementitious composites as it affects the first crack strength of the composite and the bond with fibres. The matrix with low first crack strength is desirable for strain hardening behaviour. Also, by changing the failure mechanism of fibre from rupture to debonding and pull-out the strain hardening behaviour can also be promoted. In this study, the comparison of first crack strength of DFRGC is also compared with that of DFRCC. As mentioned earlier that the correct first crack strength of fibre composite is difficult to determine from the load-deflection curve of deflection hardening composite or composite with high fibre contents, therefore, the LOP which is the end point of the linear portion of the load deflection curve is used instead of first crack strength in this study as used by others [17] and proposed in ASTM C1609. Fig. 8 shows the LOP values of all series in this study. It can be seen that the LOP values of DFRGC is equal to and even lower than that of DFRCC in some series. The deflection at LOP of DFRGC is also similar to that of DFRCC. This could be one of the reasons for similar and even better deflection hardening behaviour in some series of DFRGC.

\section{Discussion}

Generally, the deflection hardening behaviour of fibre reinforced cementitious composites is confirmed if its peak load $\left(\mathrm{P}_{\mathrm{p}}\right)$ is higher than the LOP or the first crack load $\left(\mathrm{P}_{\mathrm{LOP}}\right)$. Secondly, if the deflection at peak load $(\mathrm{Pp})$ is greater than the first crack deflection ( LOP) the deflection hardening behaviour is further promoted with enhanced ductility. This indicates that a fibre composite with Pp greater than $\mathrm{P}_{\mathrm{LOP}}$ and LOP greater than $\mathrm{Pp}_{\mathrm{p}}$ ensures deflection hardening behaviour. By increasing the gap between the $\mathrm{P}_{\mathrm{LOP}}$ and the $\mathrm{P}_{\mathrm{p}}$ and between Lop and Pp the deflection hardening can be enhanced. In this study, all DFRGCs exhibited the ratio of $\mathrm{Pp} / \mathrm{P}_{\mathrm{LOP}}$ greater than 1, which is similar to that of DFRCC. However, the more pronounced is the ratio of ${ }_{\mathrm{LOP}} / \mathrm{Pp}$ in the DFRGC. Most of the DFRGCs especially those reinforced with PVA and hybrid ST+PVA exhibited the $\mathrm{LOP}_{\mathrm{Pp}}$ ratio more than at least 
6 (see Fig. 9), which is higher than that of its cement based counterpart. This clearly indicates higher ductility of DFRGC than DFRCC. In this study the ductility of composite is considered as the ratio of ${ }_{\mathrm{LOP}} / \mathrm{Pp}$ provided the $\mathrm{Pp}>\mathrm{P}_{\mathrm{LOP}}[18]$. This illustrates that if the $\mathrm{P}_{\mathrm{p}}$ is greater than or at least equal to the $\mathrm{P}_{\mathrm{LOP}}$, the higher the ratio of $\mathrm{LOP}_{\mathrm{P}} / \mathrm{P}_{\mathrm{p}}$, the more ductile the composite is. This translates the concept of ductility index (D.I.) defined as follows:

Ductility Index (D.I.) $-\frac{\delta_{P_{p}}}{\delta_{L O P}} \quad\left(\right.$ where, $\left.P_{p} \geq P_{L O P}\right)$

The calculated D.I. according to equation (1) of both composites in this study is shown in Fig. 9 and it can be seen that the geopolymer based composites exhibited higher D.I. values $\frac{\delta_{F_{p}}}{\left(\delta_{L O P}\right)}$ than its cement based counterpart.

The superior deflection hardening of DFRGCs is also confirmed from the calculated toughness values at peak load ( $\left.\mathrm{T}_{\text {peak }}\right)$ as shown in Fig. 10. The figure shows the toughness of all DFRGC and DFRCC composites which are calculated as the area of the load-deflection curve up to the peak load. It can be seen in the figure that the $\mathrm{T}_{\text {peak }}$ is higher in all DFRGCs than the DFRCCs. This clearly indicates the higher energy absorption of DFRGCs than that of DFRCCs. The DFRGCs also exhibited higher toughness index at peak load $\left(\mathrm{I}_{\text {peak }}\right)$ than that of DFRCCs (see Fig. 11). It is mentioned earlier that the $\mathrm{I}_{\text {peak }}$ is the ratio of area of loaddeflection curve up to the peak load to that up to the LOP. The higher the $\mathrm{I}_{\text {peak }}$ value the more non-elastic energy absorption capacity of the composite is. In this study, all DFRGC exhibited higher $I_{\text {peak }}$ values than that of DFRCC (see Fig. 11). Some DFRGCs containing PVA and hybrid ST+PVA fibres exhibited very high I values of more than 20. According to Naaman and Reinhardt [18] the $\mathrm{I}_{20}>20$ is an indication of deflection hardening behaviour in fibre composites. On the contrary only few cement based composites reached this limit.

In this study, the superiority of DFRGC over DFRCC is not only evaluated upto peak load but also measured after the peak load. The flexural strength of the composites at deflection corresponding to $1 / 50^{\text {th }}$ of the span is calculated and the ratio of this value to MOR is presented in Fig. 12. It can be seen in the figure that most of the DFRGCs maintained more than $70 \%$ of their MOR at deflection corresponds to $1 / 50^{\text {th }}$ of the span, which is double the current limit stipulated in ASTM C 1609. This is another indication of superior post peak ductility of DFRGC over its counterpart DFRCC. 


\section{Microstructure observation:}

Scanning electron microscope (SEM) observation of the fibre-matrix interface and fibre surface texture were performed to characterise the fibre-matrix bond in both composites. The SEM images of fibre-matrix interface of DFRGC and DFRCC are shown in Figs. 13-14. Fig. 13 shows the fibre-matrix interface of steel fibre reinforced composites. A relatively smooth steel fibre surface is observed in the fly ash based geopolymer composite, whereas slight rough steel fibre surface with cement hydration products is observed in the cement composite. The observed higher flexural strength of steel fibre reinforced DFRCC compared to its counterpart DFRGC is due to this bond behaviour. In the case of PVA fibre reinforced cement composite superior bond between the fibre and the matrix is observed as shown in Fig. 14. The figure shows rough PVA fibre surface with cement hydration products indicating better bond, whereas, less geopolymer products is observed on the PVA fibre surface. This clearly corresponds to the observed higher flexural strength in PVA fibre reinforced DFRCC than that of DFRGC. The measured diameter of both steel and PVA fibres in geopolymer composite also found to be unchanged, indicating no adverse effect on the degradation of the PVA fibre in slightly high alkaline geopolymer matrix.

\section{Conclusions:}

Within limited experimental program in this study the following conclusions can be made:

1) Deflection hardening behaviour is achieved in the DFRGC similar to that observed in the DFRCC.

2) The first crack load or in other word the limit of proportionality (LOP) of DFRGC is similar to that of DFRCC.

3) The DFRGC exhibited higher deflection at peak load than DFRCC.

4) The toughness at peak load of DFRGC is higher than that of DFRCC.

5) The ductility of DFRGC is also higher than that of DFRCC.

6) The alkalinity of geopolymer matrix did not affect the degradation of PVA and steel fibre as observed in the SEM study.

7) More geopolymeric products are observed on the PVA fibre surface in the cement composite than that of geopolymer composite in the SEM study, indicating higher 
bond between the PVA fibre and geopolymer matrix than that of PVA-cement matrix system.

\section{Acknowledgement}

Grateful acknowledgement is due to Kuraray Co. Ltd. of Japan for supplying the PVA fibre and BOFSA Co Ltd. for supplying the Dramix (steel) fibre. The author would like to acknowledge the assistance of final year project student Mr. Yee Yong Lu during the course of this investigation.

\section{References}

[1] Naaman, A.E. and Reinhardt, H.W. (2006), Proposed classification of HPFRC composites on their tensile response, Materials and structures, Vol. 39, pp. 547-555.

[2] Li, V.C. and Wu, H.C. (1992). “Conditions for pseudo strain-hardening in fibre reinforced brittle matrix composites”, Applied Mech Review, 45(8), 390-398.

[3] JCI-DFRCC Committee, (2003) Technical report on the terminology, Journal of Advanced Concrete Technology, 1(3): 335-340.

[4] Ahmed, S.F.U. Maalej, M. and Paramasivam, P. (2006). Flexural responses of hybrid steel-polyethylene fibre reinforced cement composites containing high volume fly ash. Journal of construction and building materials, 21: 1088-1097.

[5] Hardjito, H. and Rangan, B.V. (2005) Development and properties of low-calcium fly ash based geopolymer concrete, Research report GCI. Faculty of engineering, Curtin University, Perth, Australia.

[6] Rangan, B.V. (2007) Low calcium fly ash bsed geopolymer concrete. In: Nawy EG editor. Concrete construction engineering handbook. New York, CRC press.

[7] Yunsheng, Z., Zongjin, S.W. and Xiangming, Z. (2009), Geopolymer extruded composites with incorporated flyash and polyvinyl alcohol short fibre, ACI materials journal, 106(1): 3-10.

[8] Li, W. and Xu, J. (2009), Mechanical properties of basalt fiber reinforced geopolymeric concrete under impact loading, Materials science and engineering-A, 505: 178-186.

[9] Bernal, S., Gutierrez, D., Delvasto, S. and Rodriguez, E. (2006), Performance of geopolymeric concrete reinforced with steel fibers, In the proceedings of $10^{\text {th }}$ international inorganic bonded fiber composites, Sao Paulo, Brazil.

[10] Natali, A., Manzi, S. and Bignozzi, M.C. (2011) Novel fibre reinforced composite materials based on sustainable geopolymer matrix, Procedia engineering, 21, 1124-1131. 
[11] Zhang, Z., Yao, X., Zhu, H. and Hua, S. (2009) Preparation and mechanical properties of polypropylene fibre reinforced calcined kaolin-fly ash based geopolymer , Journal of central southern university of Technology, 16, 49-52.

[12] Zhang, Y., Sun, W. and Li, Z. (2006) Impact behaviour and microstructural characteristics of PVA fibre reinforced fly ash geopolymer boards prepared by extrusion technique, Journal of materials science, 41, 2787-2794.

[13] Zhang, Y., Sun, W. and Li, Z., Eddie, and Chungkong, C. (2008)Impact properties of geopolymer based extrudates incorporated with fly ash and PVA short fibre, Construction and building materials, 22, 370-383.

[14] Sarker, P.K., Haque, R. and Ramgolam, K.V. (2013) Fracture behaviour of heat cured fly ash based geopolymer concrete, Materials and Design, 44:580-586.

[15] Pan, Z., Sanjayan, J.G. and Rangan, B.V. (2011) Fracture properties of geopolymer paste and concrete, Magazine of concrete research, 63(10):763-771.

[16] Temuujin, J., Riessen, A.V. and MacKenzie, K. (2010), Preparation and characterisation of fly ash based geopolymer mortars, Journal of construction and building materials, 24 : 1906-1910.

[17] Kim, D.J., Naaman, A.E. and El-Tawil, S. (2008) Comparative flexural behaviour of four reinforced cementitious composites, cement and concrete composites, 30: 917-928.

[18] Naaman, A.E. and Reinhardt, H.W., (1995) “Characterization of high performance fibre reinforced cement composites”, Proceedings of the Second International RILEM Workshop, USA, June 1995, pp. 1-24.

[19] Ahmed, S.F.U and Mihashi, H. (2011) Strain hardening behaviour of lightweight hybrid polyvinyl alcohol (PVA) fibre reinforced cement composites, Materials and structures, 44:1179-1191. 
Table 1. Experimental program and mix proportions

\begin{tabular}{|c|c|c|c|c|c|c|c|c|c|c|}
\hline \multirow{3}{*}{$\begin{array}{l}\text { Comp- } \\
\text { osite } \\
\text { types }\end{array}$} & \multirow{3}{*}{$\begin{array}{l}\text { Series } \\
\text { no. }\end{array}$} & \multirow{2}{*}{\multicolumn{2}{|c|}{$\begin{array}{l}\text { Fibre types } \\
\text { (by volume) }\end{array}$}} & \multicolumn{7}{|c|}{ Mix proportions by wt. } \\
\hline & & & & \multirow[t]{2}{*}{ Cement } & \multirow{2}{*}{$\begin{array}{l}\text { Class F } \\
\text { fly ash }\end{array}$} & \multicolumn{2}{|c|}{ Sand/Binder } & \multirow{2}{*}{$\begin{array}{l}\text { Water/ } \\
\text { cement }\end{array}$} & \multicolumn{2}{|c|}{$\begin{array}{l}\text { Alkali activator/ } \\
\text { fly ash }\end{array}$} \\
\hline & & Steel & PVA & & & $\begin{array}{l}\mathrm{d}_{\max }= \\
1.18 \mathrm{~mm}\end{array}$ & $\begin{array}{l}\mathrm{d}_{\max }= \\
0.6 \mathrm{~mm}\end{array}$ & & $\begin{array}{l}\mathrm{NaOH} \\
(8 \mathrm{M})\end{array}$ & $\mathrm{Na}_{2} \mathrm{SiO}_{3}$ \\
\hline \multirow{5}{*}{ 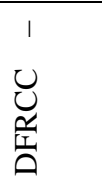 } & \multirow[t]{3}{*}{1} & $2 \%$ & - & \multirow{3}{*}{1} & \multirow{3}{*}{ - } & \multirow{3}{*}{0.75} & \multirow{3}{*}{ - } & \multirow{3}{*}{0.45} & & \multirow{3}{*}{-} \\
\hline & & - & $2 \%$ & & & & & & & \\
\hline & & $1 \%$ & $1 \%$ & & & & & & & \\
\hline & \multirow[t]{3}{*}{2} & $2 \%$ & - & \multirow{3}{*}{1} & \multirow{3}{*}{ - } & \multirow{3}{*}{0.5} & \multirow{3}{*}{-} & \multirow{3}{*}{0.45} & \multirow{3}{*}{ - } & \multirow{3}{*}{-} \\
\hline & & - & $2 \%$ & & & & & & & \\
\hline \multirow{3}{*}{ 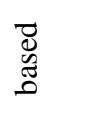 } & & $1 \%$ & $1 \%$ & & & & & & & \\
\hline & 3 & $2 \%$ & - & \multirow{3}{*}{1} & \multirow{3}{*}{ - } & \multirow{3}{*}{-} & \multirow{3}{*}{0.75} & & & \\
\hline & & - & $2 \%$ & & & & & 0.45 & - & - \\
\hline & & $1 \%$ & $1 \%$ & & & & & & & \\
\hline 믈 & 4 & $2 \%$ & - & & & & & & & \\
\hline$U$ एँ & & - & $2 \%$ & 1 & - & - & 0.5 & 0.45 & - & - \\
\hline & & $1 \%$ & $1 \%$ & & & & & & & \\
\hline & 5 & $2 \%$ & - & & & 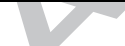 & & & & \\
\hline ن & & - & $2 \%$ & - & 1 & 0.75 & - & - & 0.13 & 0.32 \\
\hline 唗 & & $1 \%$ & $1 \%$ & & & & & & & \\
\hline A & 6 & $2 \%$ & - & & & & & & & \\
\hline ד & & - & $2 \%$ & - & 1 & 0.5 & - & - & 0.13 & 0.32 \\
\hline$\tilde{\tilde{D}}$ & & $1 \%$ & $1 \%$ & & & & & & & \\
\hline & 6 & $2 \%$ & & & & & & & & \\
\hline ذ্ت & & - & $2 \%$ & & 1 & - & 0.75 & - & 0.13 & 0.32 \\
\hline S & & $1 \%$ & $1 \%$ & 2 & & & & & & \\
\hline 官= & 8 & $2 \%$ & 2 & & & & & & & \\
\hline ᄋ & & - & $2 \%$ & - & 1 & - & 0.5 & - & 0.13 & 0.32 \\
\hline 0 & & $1 \%$ & $1 \%$ & & & & & & & \\
\hline
\end{tabular}

Note: Binder $=$ Cement or fly ash

Table 2. Chemical compositions of fly ash

\begin{tabular}{|c|c|c|c|c|c|c|c|c|}
\hline $\mathrm{SiO}_{2}$ & $\mathrm{Al}_{2} \mathrm{O}_{3}$ & $\mathrm{Fe}_{2} \mathrm{O}_{3}$ & $\mathrm{CaO}$ & $\mathrm{MgO}$ & $\mathrm{SO}_{3}$ & $\mathrm{Na}_{2} \mathrm{O}$ & $\mathrm{K}_{2} \mathrm{O}$ & LOI \\
\hline $51.5 \%$ & $23.63 \%$ & $15.3 \%$ & $1.74 \%$ & $1.2 \%$ & $0.28 \%$ & $0.38 \%$ & $0.84 \%$ & $1.78 \%$ \\
\hline
\end{tabular}

Table 3. Properties of fibre

\begin{tabular}{|c|c|c|c|c|c|c|}
\hline $\begin{array}{l}\text { Types of } \\
\text { Fibre }\end{array}$ & $\begin{array}{l}\text { Length } \\
(\mathrm{mm})\end{array}$ & $\begin{array}{l}\text { Diameter } \\
(\mathrm{mm})\end{array}$ & $\begin{array}{c}\text { Modulus of } \\
\text { elasticity } \\
(\mathrm{MPa})\end{array}$ & $\begin{array}{c}\text { Fibre } \\
\text { Strength } \\
(\mathrm{MPa})\end{array}$ & $\begin{array}{c}\text { Density } \\
\left(\mathrm{gm} / \mathrm{cm}^{3}\right)\end{array}$ & Elongation (\%) \\
\hline PVA & 8 & 0.04 & 40,000 & 1,600 & 1.3 & 6 \\
\hline Steel & 10 & 0.12 & 200,000 & 2,500 & 7.8 & - \\
\hline
\end{tabular}




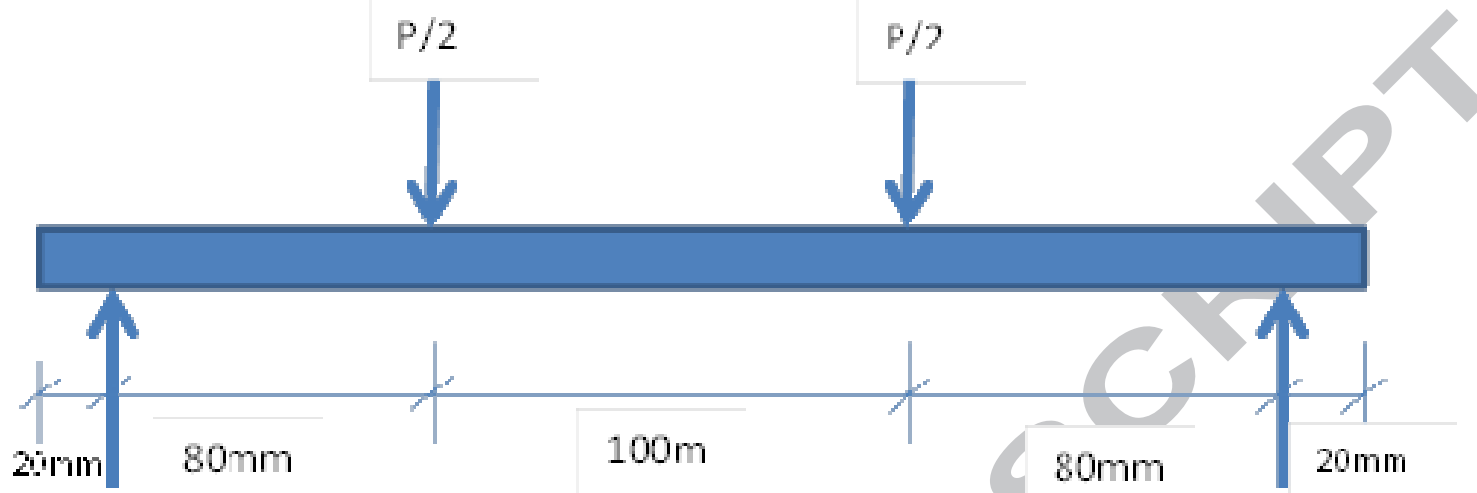

Fig. 1. Bending test setup

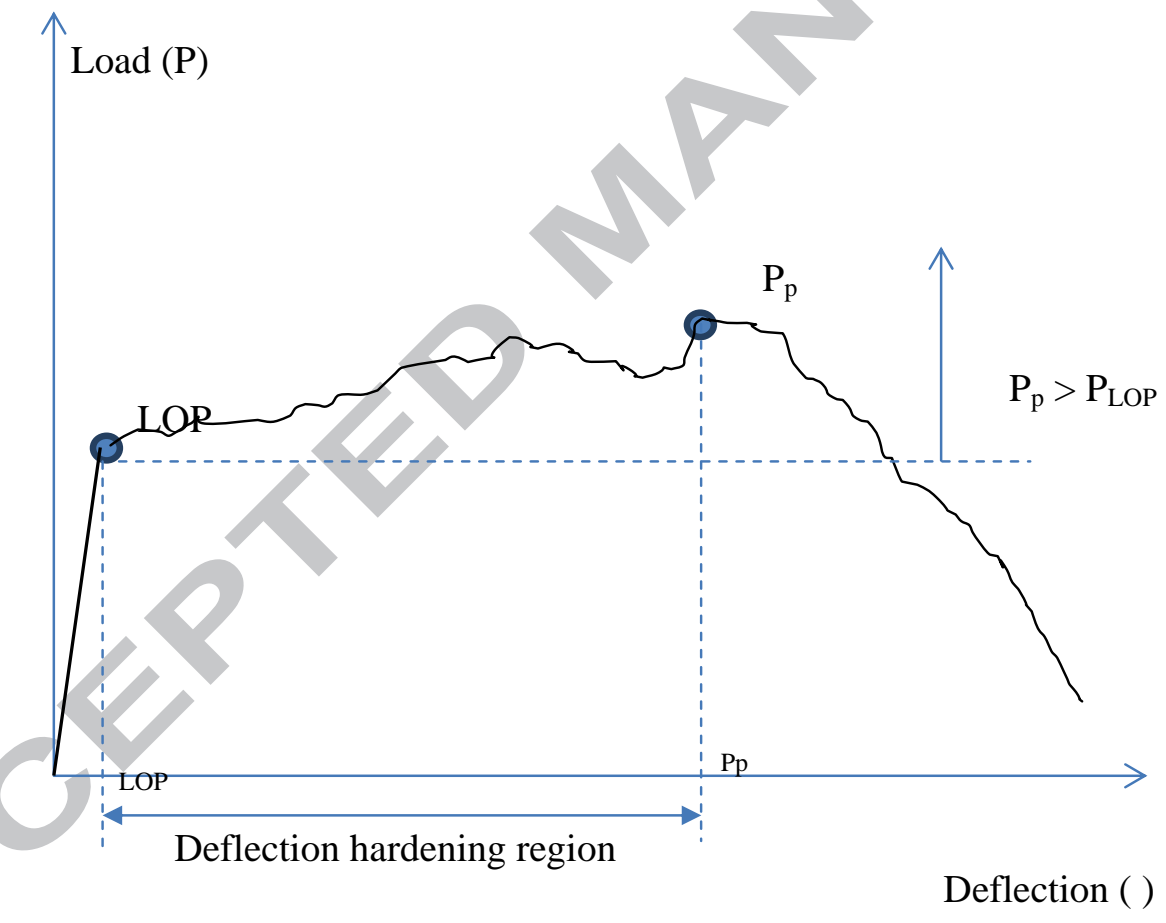

Fig. 2. Typical deflection hardening behaviour of DFRCC. 


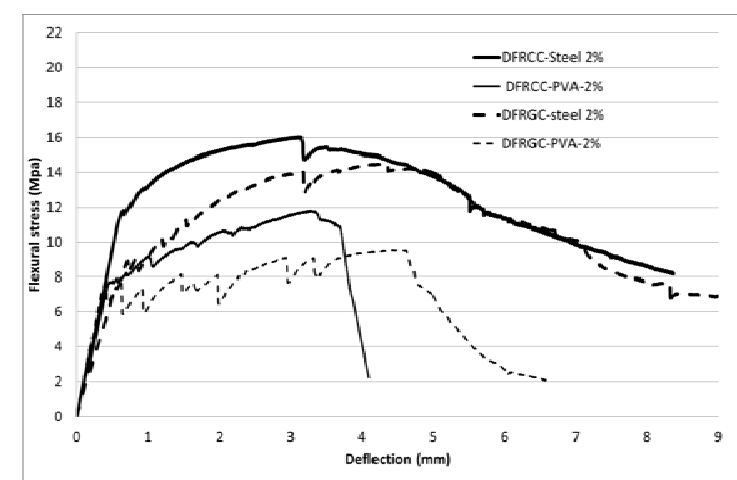

(a) Sand/binder $=0.5$

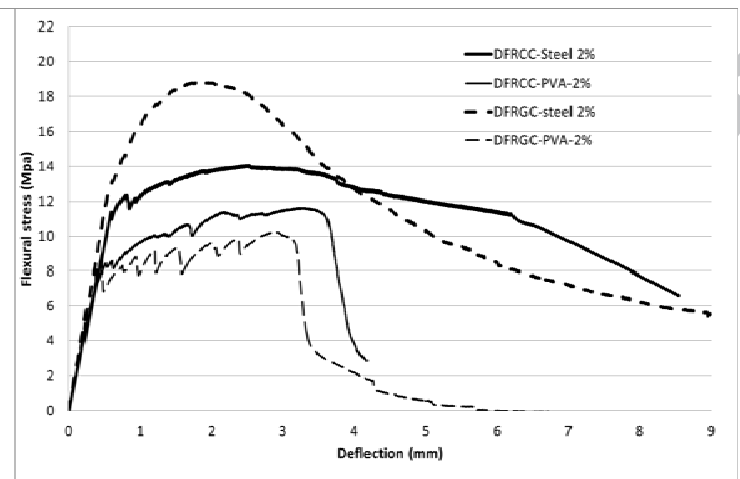

(b) Sand/binder $=0.75$

Fig. 3 Deflection hardening behaviour of mono fibre DFRCC and DFRGC with maximum sand size of $0.6 \mathrm{~mm}$

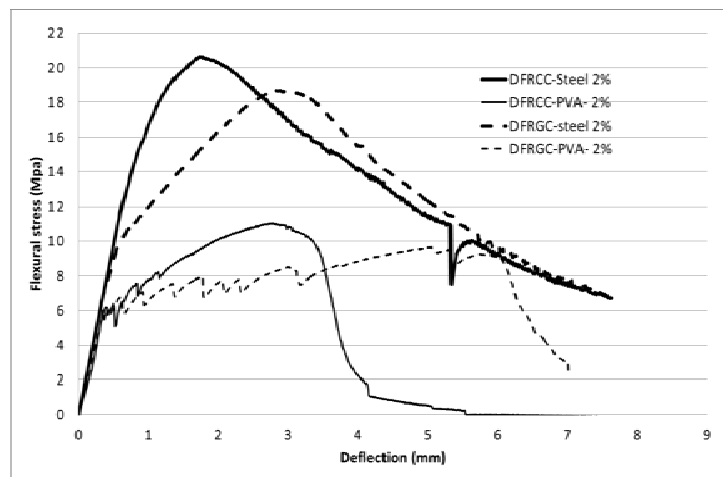

(a) Sand/binder $=0.5$

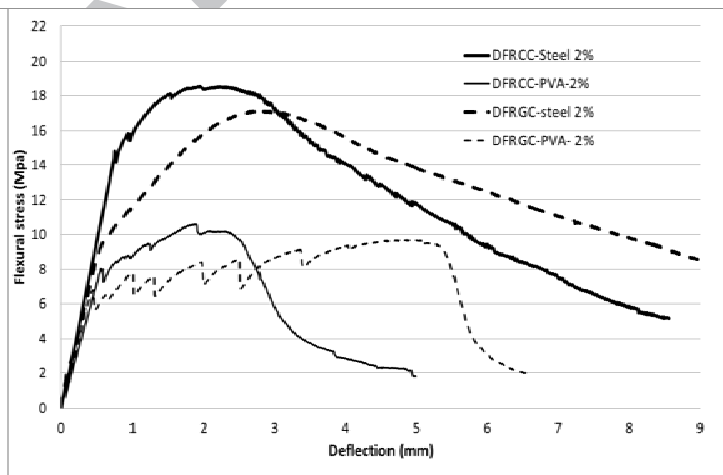

(b) Sand/binder $=0.75$

Fig. 4 Deflection hardening behaviour of mono fibre DFRCC and DFRGC with maximum sand size of $1.18 \mathrm{~mm}$ 


\section{ACCEPTED MANUSCRIPT}

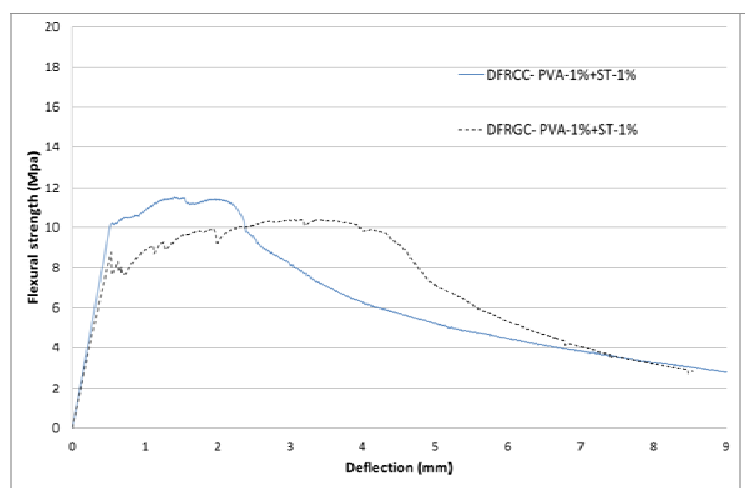

(a) Sand/binder $=0.5$

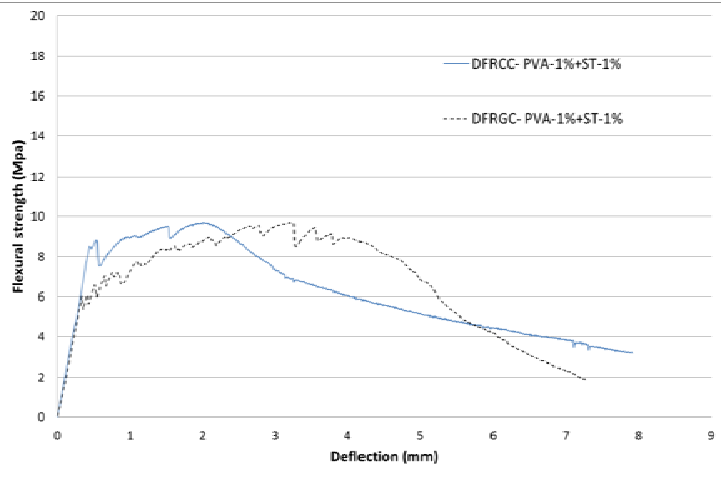

(b) Sand/binder $=0.75$

Fig. 5 Deflection hardening behaviour of hybrid fibre DFRCC and DFRGC with maximum sand size of $0.6 \mathrm{~mm}$

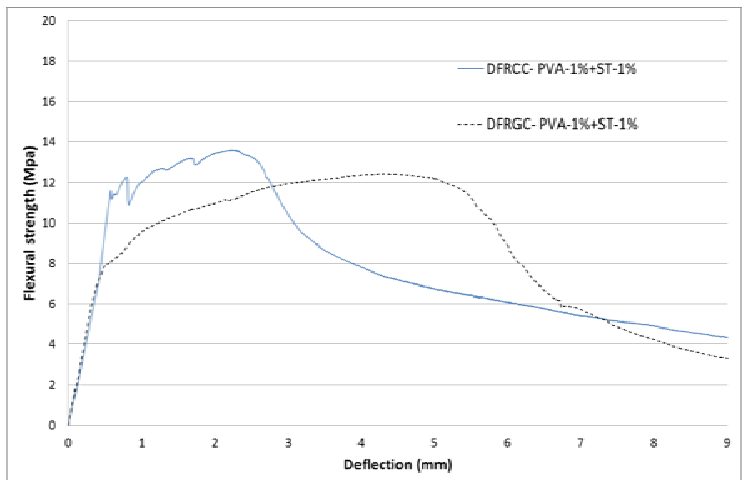

(a) Sand/binder $=0.5$

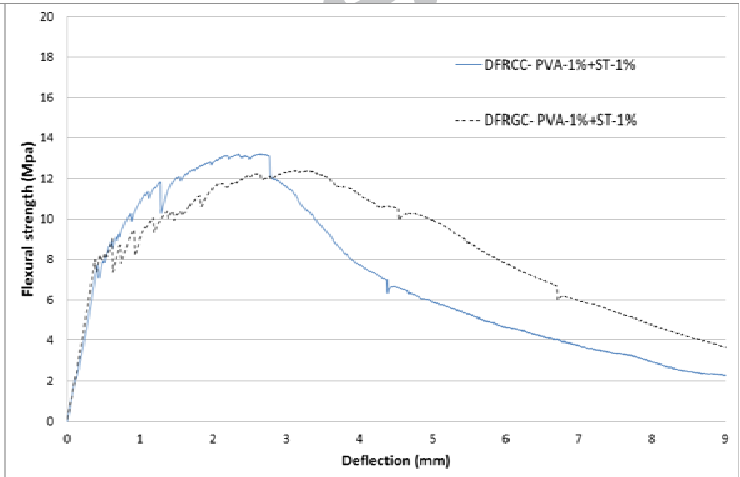

(b) Sand/binder $=0.75$

Fig.6 Deflection hardening behaviour of hybrid fibre DFRCC and DFRGC with maximum sand size of $1.18 \mathrm{~mm}$ 


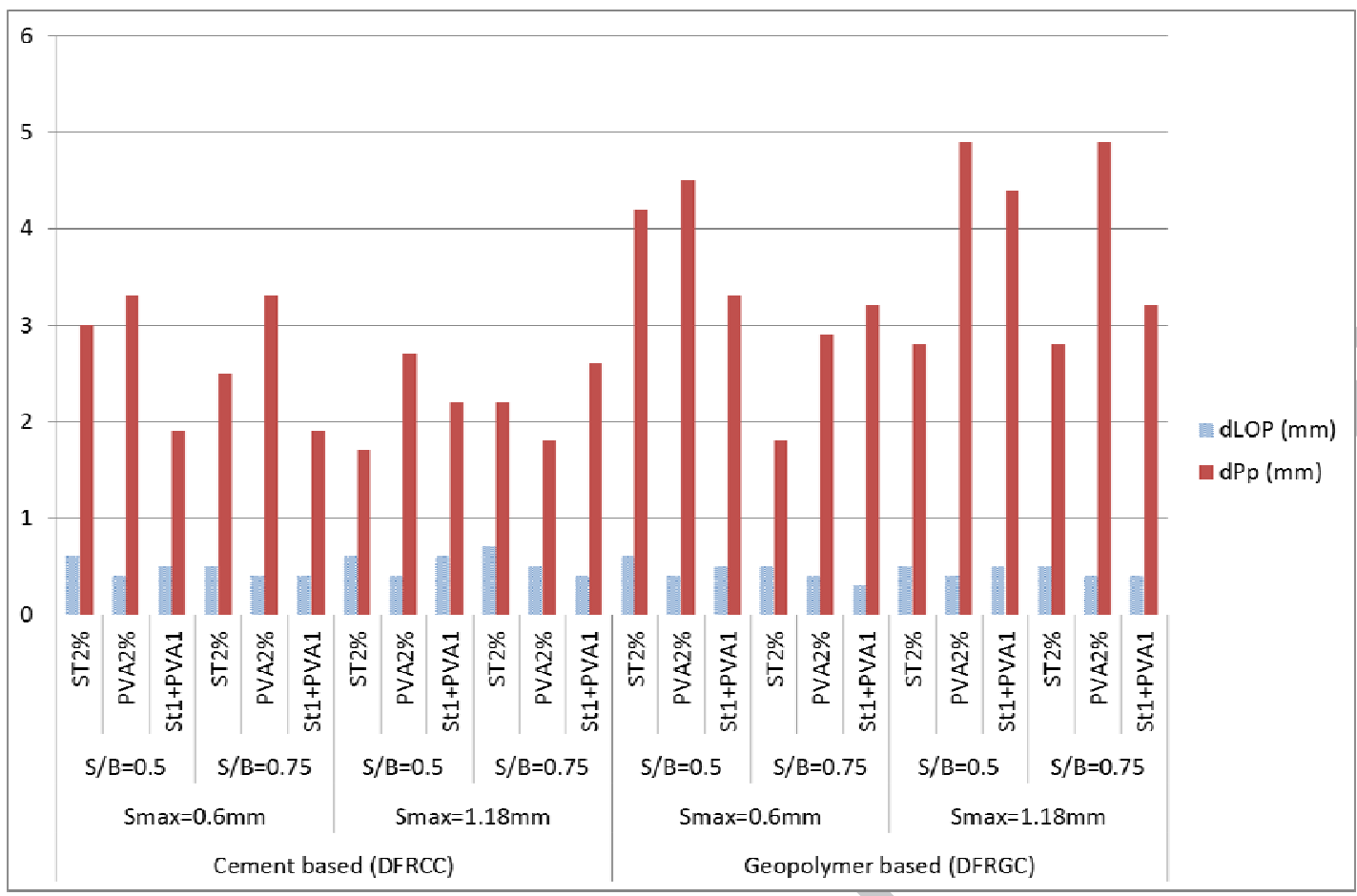

Fig. 7. Deflection at LOP and at peak load of all series.

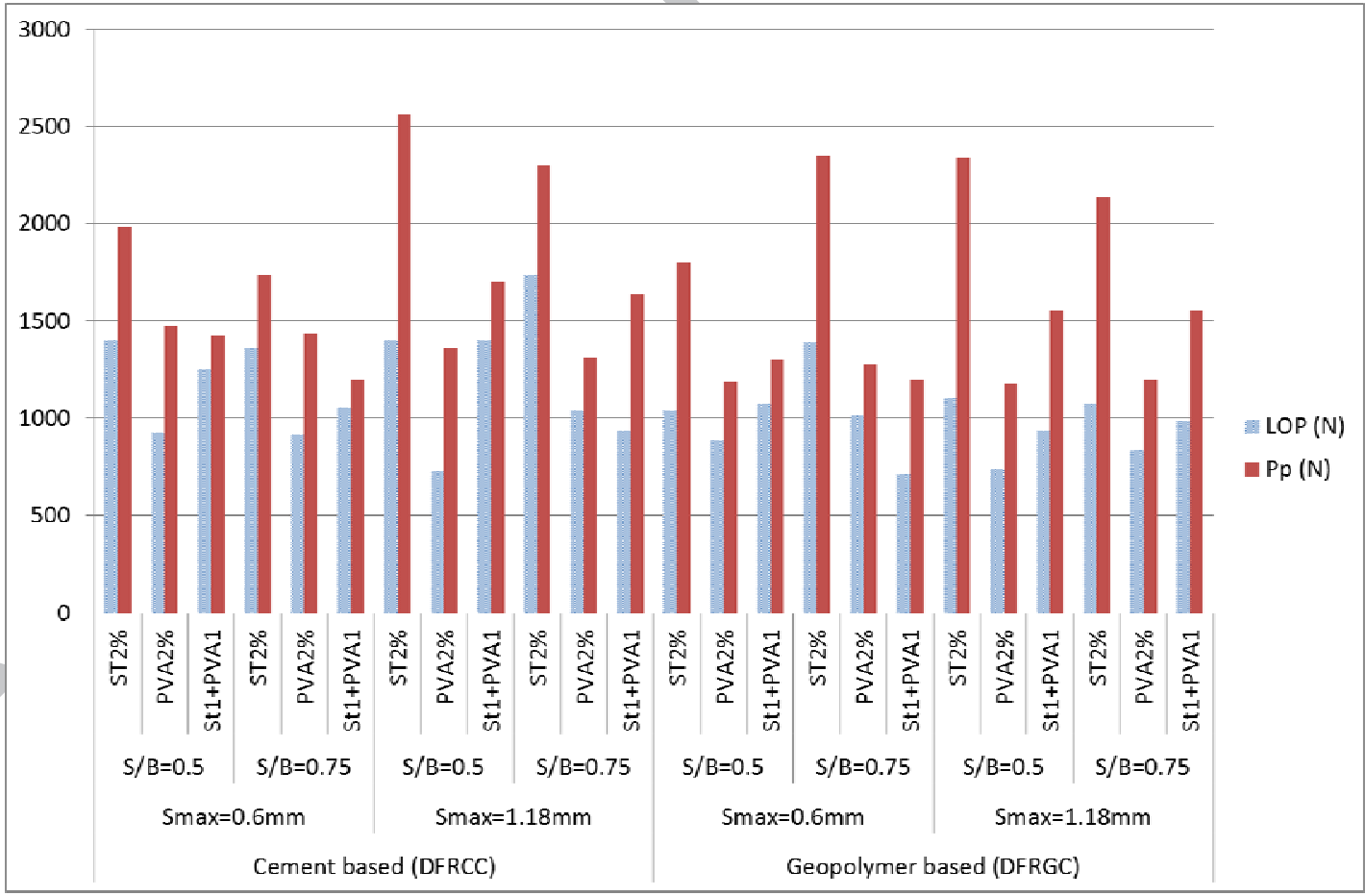

Fig. 8 Limit of proportionality (LOP) and peak load values of all series. 


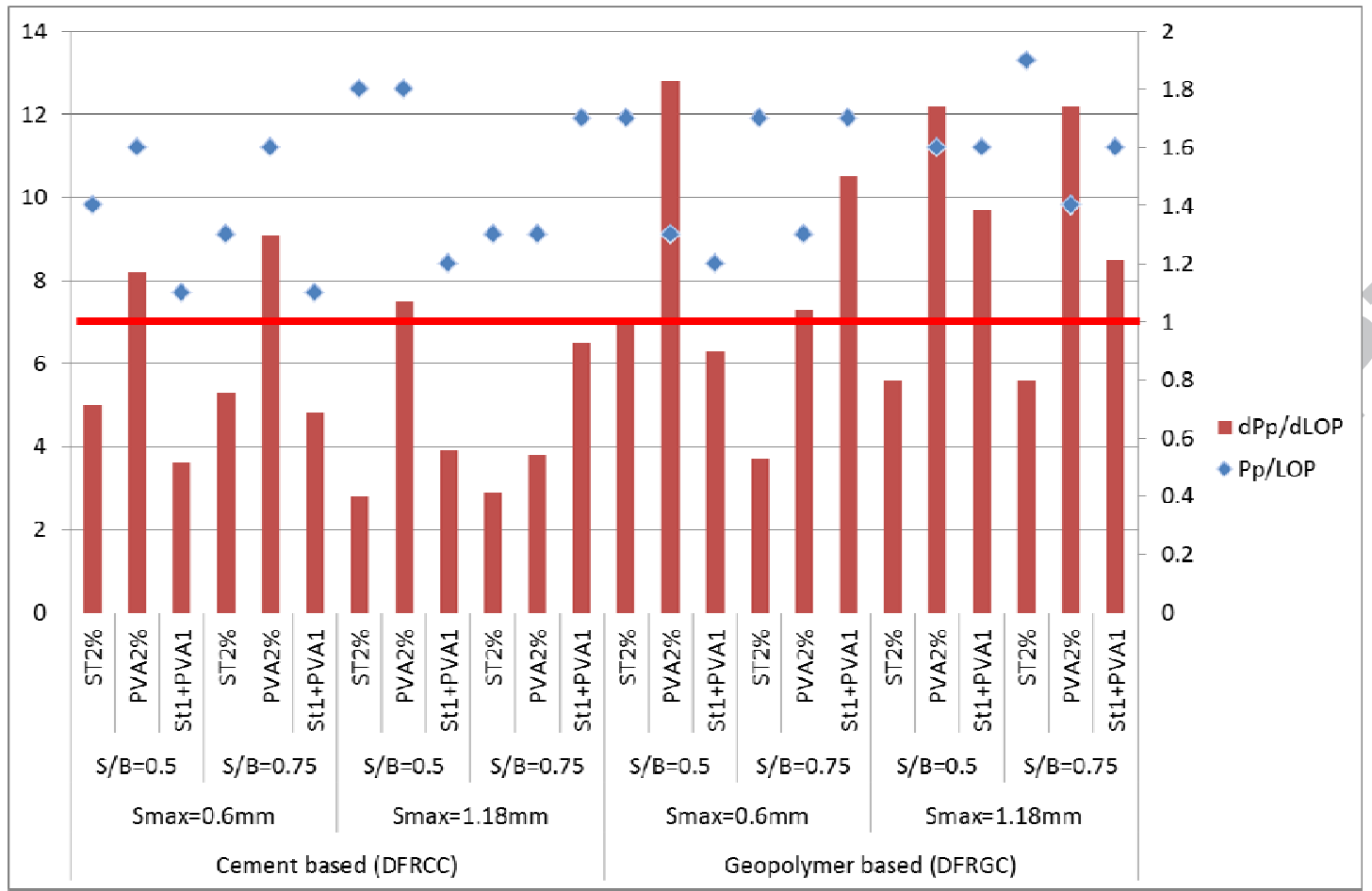

Fig. 9. Ratios of peak load to LOP and deflection at peak load to that at LOP (also known as ductility index, DI) of all series.

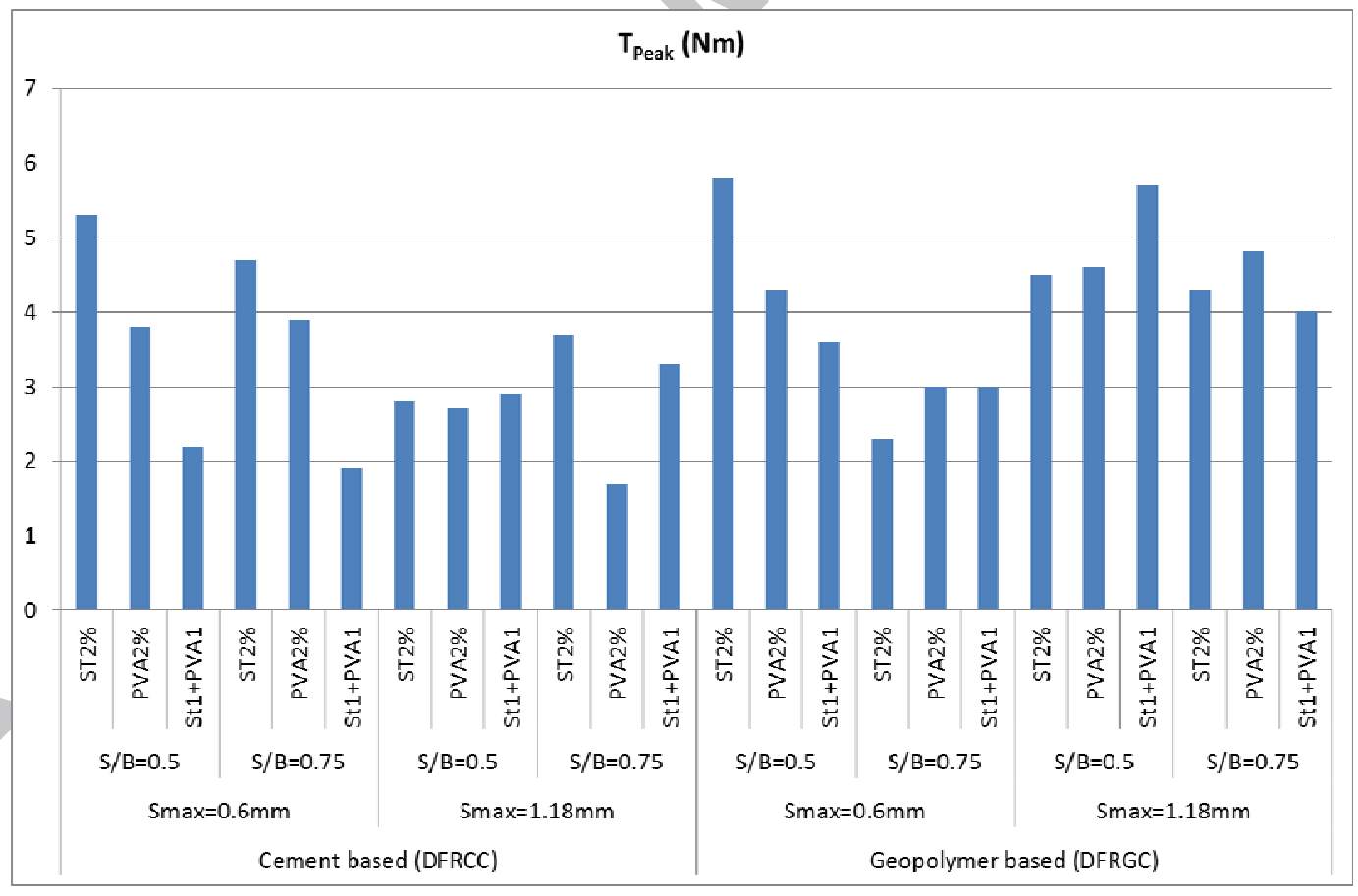

Fig. 10. Calculated toughness up to peak load $\left(T_{\text {peak }}\right)$ of all series. 


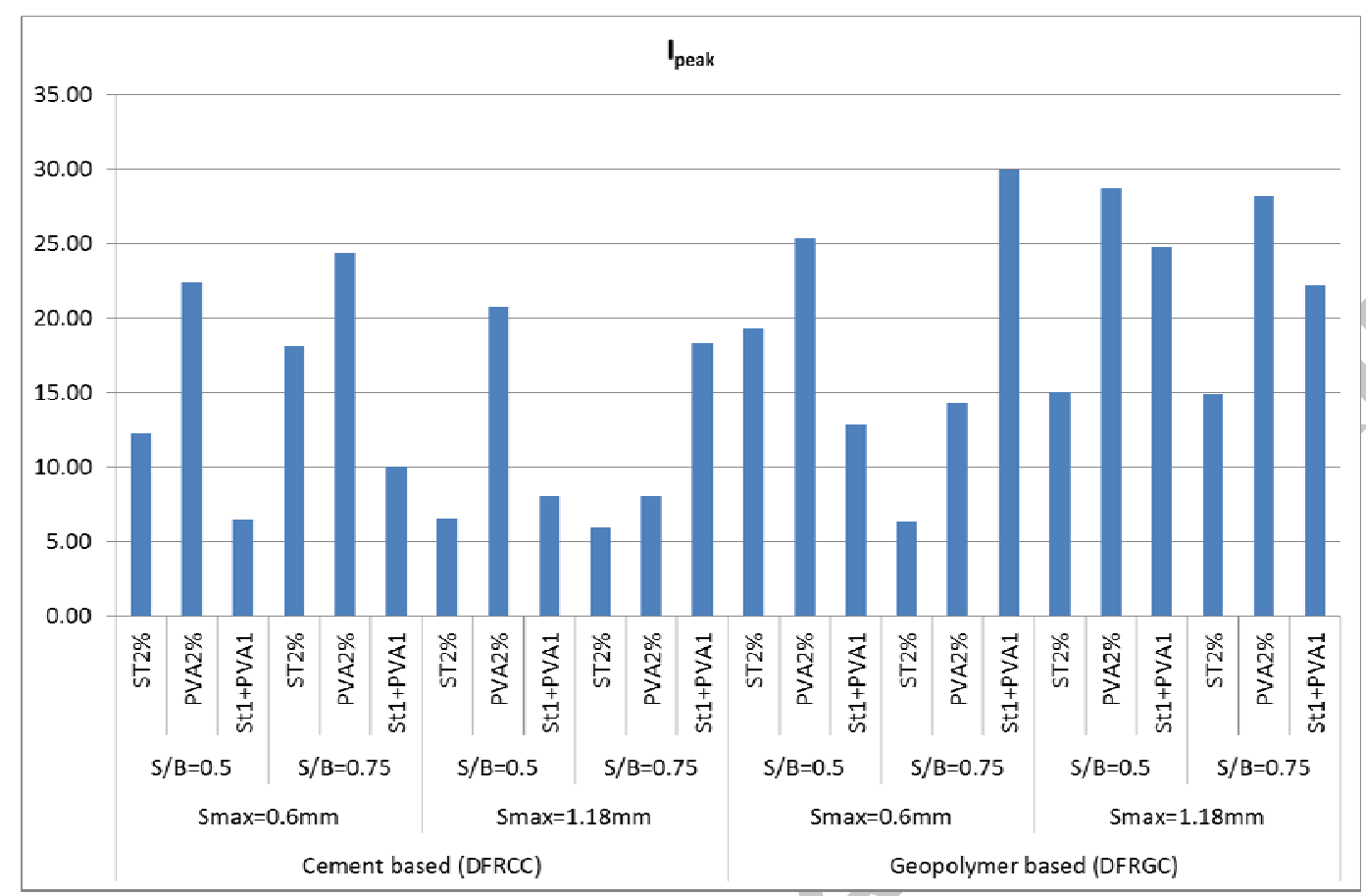

Fig. 11. Calculated toughness index up to peak load $\left(I_{\text {peak }}\right)$ of all series.

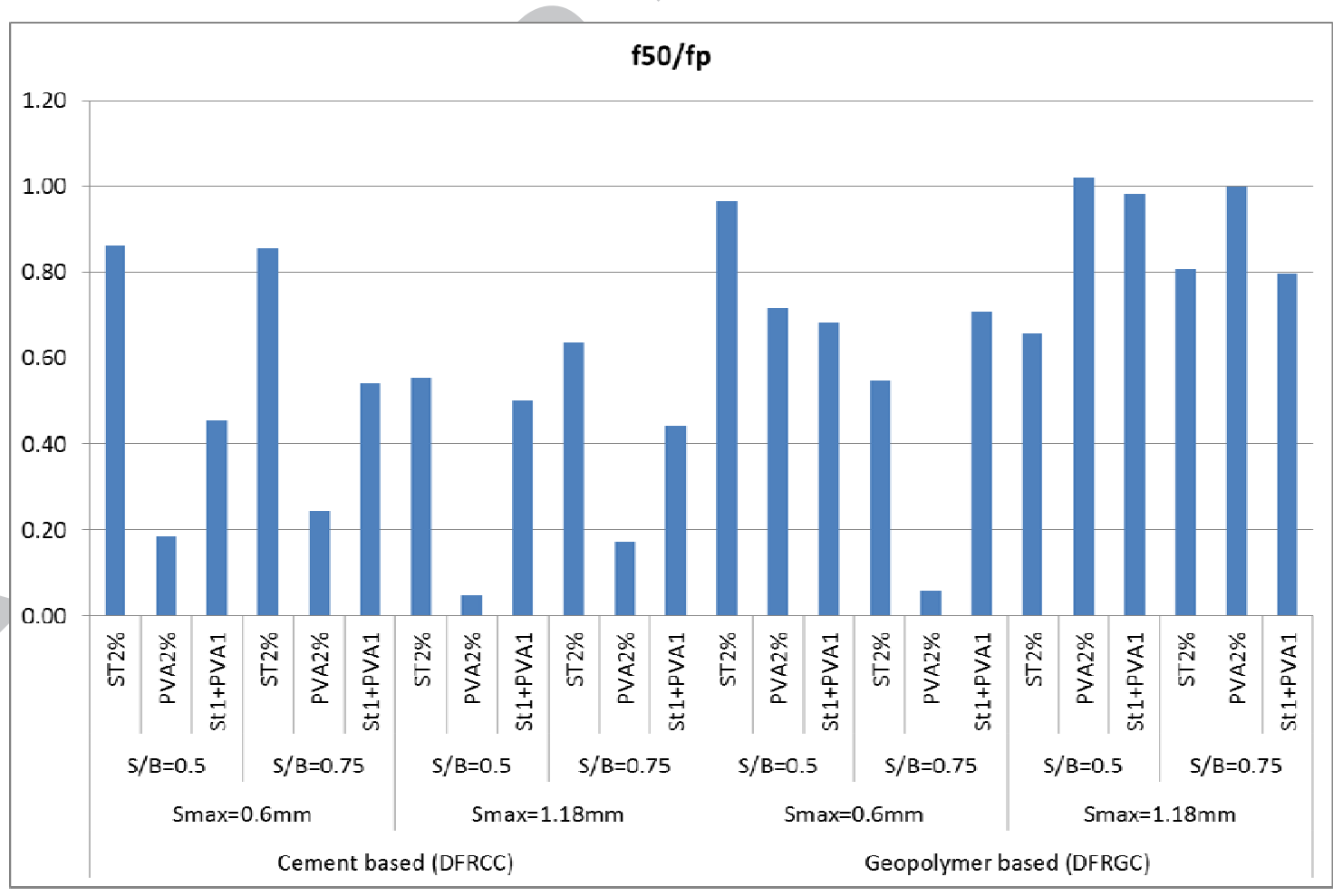

Fig. 12. Ratio of flexural strength at deflection of span/50 to that at peak load. 

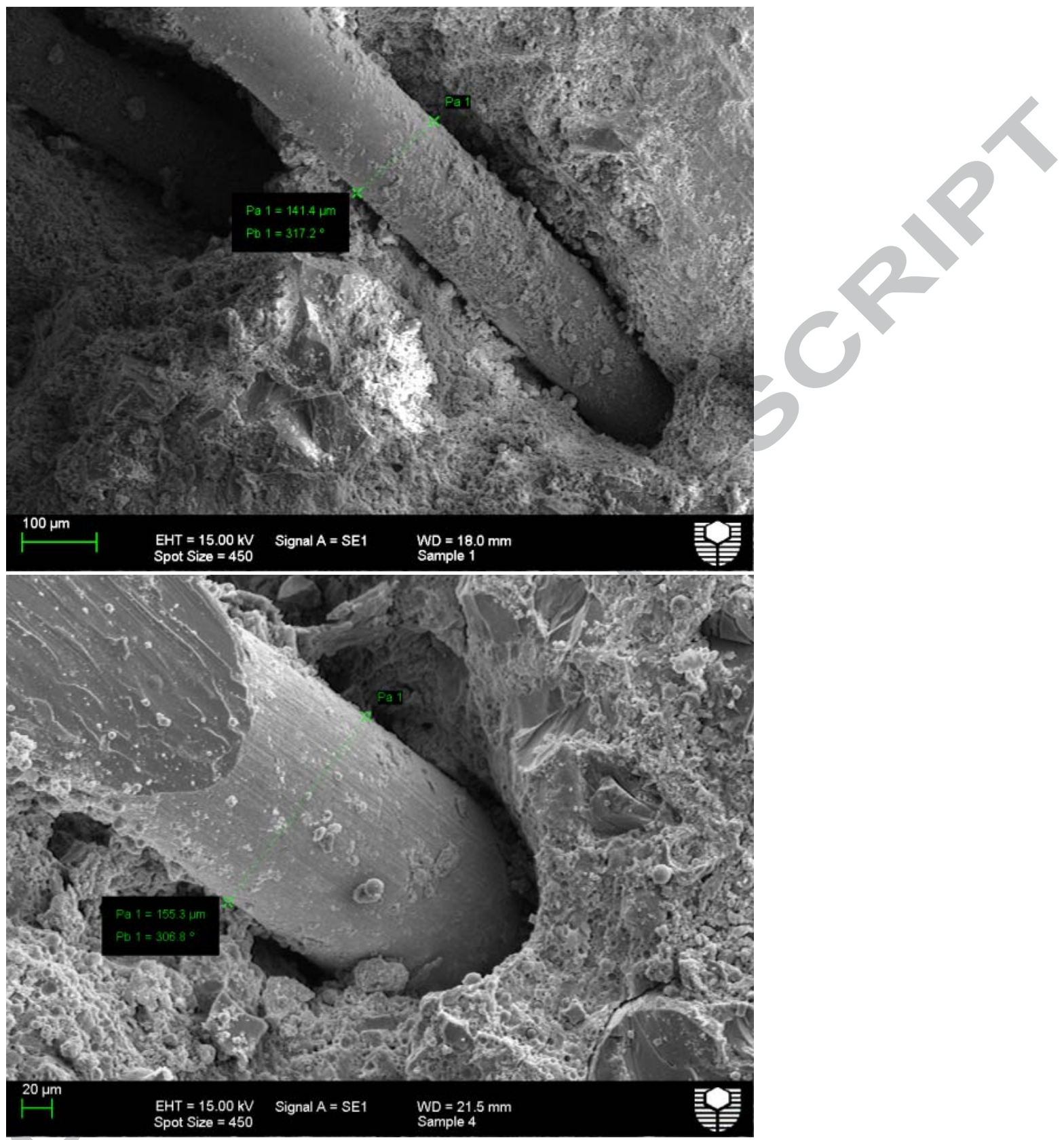

Fig. 13 SEM image of steel fibre in cement matrix (top) and fly ash based geopolymer matrix (bottom) 

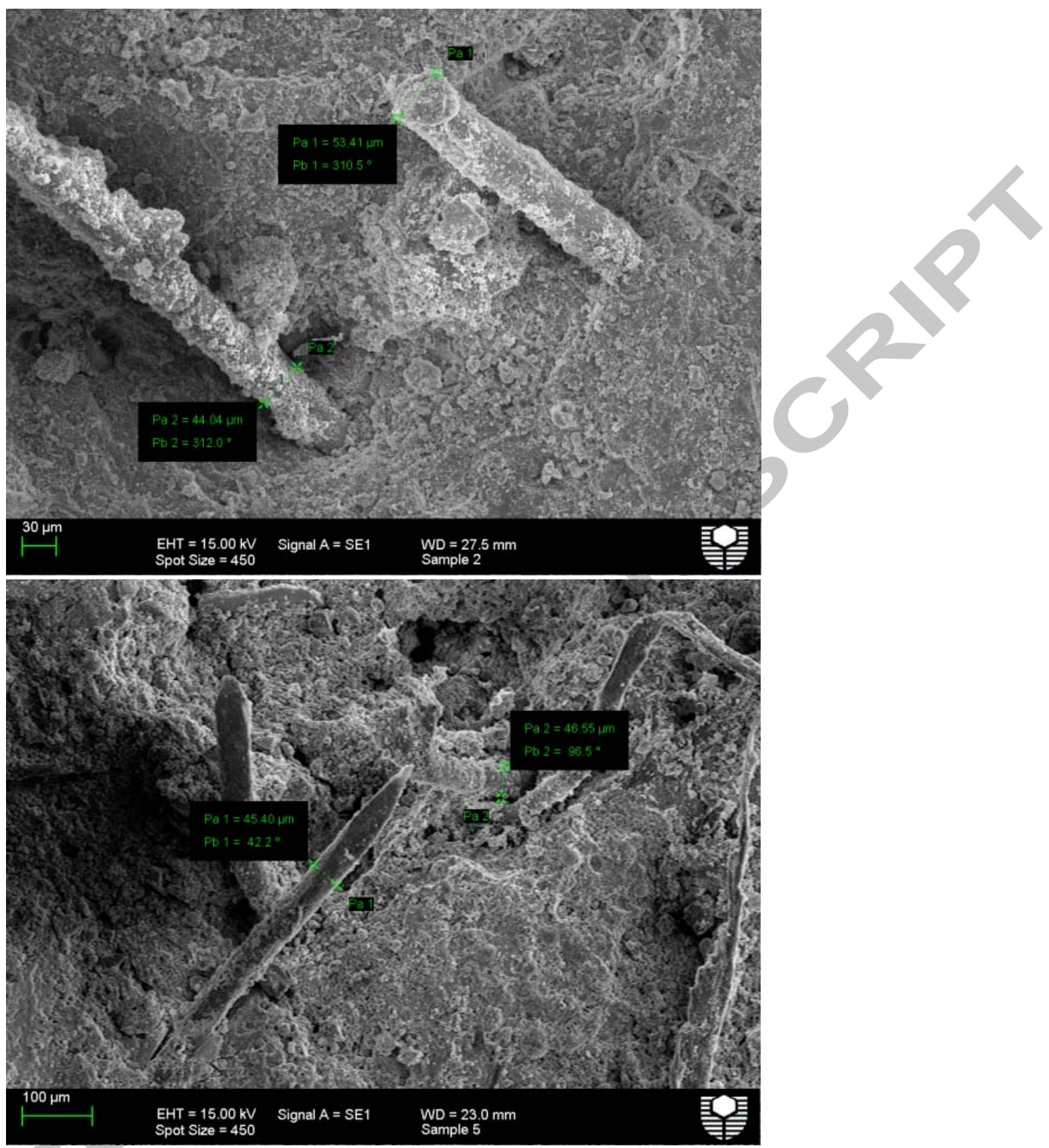

Fig. 14 SEM image of PVA fibre in cement matrix (top) and fly ash based geopolymer matrix (bottom) 
1. Deflection hardening behaviour is achieved in the DFRGC similar to that observed in DFRCC.

2. The first crack load or in other word the limit of proportionality (LOP) of DFRGC is similar to that of DFRCC.

3. The DFRGC also exhibited higher deflection at peak load than DFRCC.

4. The toughness at peak load of DFRGC is also high than that of DFRCC.

5. The ductility of DFRGC is also higher than that of DFRCC. 